\title{
Integrated Water Resources Management and Poverty Eradication -Policy Analysis of Bangladesh and Cameroon
}

\author{
Emmanuel M. Nyambod, Huq Nazmul \\ Department of Human Ecology, Vrije Universiteit Brussel, Brussels, Belgium \\ E-mail: enyambod@yahoo.co.uk,nazmulhuqrussell@gmail.com \\ Received December 18, 2009; revised December 25, 2009; accepted January 27, 2010
}

\begin{abstract}
There is a growing recognition that the world faces water crisis that, left unchecked, will derail progress towards the Millennium Development Goals and hold back human development. Water for life in the household and water for livelihoods through production are two of the foundations for human development. This paper argues that the roots of the crisis in water can be traced to poverty, inequality and unequal power relationships, as well as flawed water management policies that exacerbate scarcity. Structured discussion on the basis of the key elements of integrated water resource management reveals that despite of more or less equivalent economic structure of both Bangladesh and Cameroon, both countries do not necessarily have the same policies in water management. This paper therefore broadly recommends inter-country experience sharing of good practices in to be able to cope with water problems in these millennia.
\end{abstract}

Keywords: Bangladesh, Cameroon, Integrated Water Management, Policies

\section{Introduction}

The word crisis is sometimes overused in development. But when it comes to water, there is a growing recognition that the world faces a crisis that, left unchecked, will derail progress towards the Millennium Development Goals ${ }^{1}$ and hold back human development. Throughout history human progress has depended on access to clean water and on the ability of societies to harness the potential of water as a productive resource. Water for life in the household and water for livelihoods through production are two of the foundations for human development ${ }^{2}$. Yet for a large section of humanity these foundations are not in place. The reports argues that the roots of the crisis in water can be traced to poverty, inequality and unequal power relationships, as well as flawed water management policies ${ }^{3}$ that exacerbate scarcity.

\subsection{Human Development, Poverty and Water- Looking for the Link}

Access to water for life is a basic human need and a fun-

\footnotetext{
${ }^{1}$ UN-DESA. 2008. The Millennium Development Goals Report 2008. United Nations. New York.

${ }^{2}$ www.hdr.undp.org/en/media/HDR06-complete.pdf accessed on 25/04 $/ 2009$.
}

damental human right ${ }^{4}$. Yet in our increasingly prosperous world, more than 1 billion people are denied the right to clean water and 2.6 billion people lack access to adequate sanitation 5 . These headline numbers capture only one dimension of the problem. Every year some 1.8 million children die as a result of diarrhea ${ }^{6}$ and other diseases caused by unclean water and poor sanitation. At the start of the $21^{\text {st }}$ century unclean water is the world's second biggest killer of children. Besides, every day millions of women and young girls collect water for their families - a historical ritual that reinforces gender inequalities in employment and education. Meanwhile, the ill health associated with deficits in water and sanitation undermines productivity and economic growth, reinforcing the deep inequalities that characterize current patterns of globalization and trapping vulnerable households in cycles of poverty.

\footnotetext{
${ }^{3}$ Michel, D., Pandya, A. (Ed.) 2009. Troubled Waters-Climate Change Hydro-politics, and Transboundary Resources. The Henry L. Stimson Center. ISBN: 978-0-9821935-2-5. Washington.

${ }^{4}$ http://www.gwpforum.org/gwp/library/GWP_Strategy_2009-2013_final.pdf accessed on 19/03/2009.

${ }^{5}$ WHO/UNICEF Joint Monitoring Programme for Water Supply and Sanitation; Meeting the MDG drinking water and sanitation target: a mid-term assessment of progress, 2004.

${ }^{6} \mathrm{http}: / / \mathrm{www}$. who.int/water_sanitation_health/diseases/ascariasis/en/accessed on $05 / 05 / 2009$
} 


\subsection{Integrated Water Resource Management and Poverty-Potential Remedy}

At its simplest, Integrated Water Resources Management (IWRM) is a logical and appealing concept. Its basis is that the many different uses of water resources are interdependent. Interdependency among the components holds strong backward and forward linkage amongst sociophysical variable necessary for establishment of fundamental rights of ensuring water for decent living. IWRM addresses the deep-rooted problems that exacerbate poverty and simultaneously seeks cure from the water trapped poverty. The inter-related framework of IWRM includes vital components to manage the water problem which evenly valid for the water scared countries and developed countries as well though problem matters according to the context.

This report aims to establish a relation among three basic components i.e. IWRM, Poverty and Human Development. The issues are reinforcing each other and one's performance no matter satisfactory or unsatisfactory, influences other twos. It is now widely accepted dogma for achieving global target of ensuring decent living; poverty is the major hindrance which again is aggravated by water related poverty. On this conjecture, it seems IWRM can perform the more inclusive role than any other tools.

\subsection{Scope of the Report}

The paper contains huge potentiality to explore to both explicit and implicit role of IWRM for investigating of poverty eradicating role. The major highlights of this report concern two developing countries with versatile geo-sociological context, i.e. Bangladesh and Cameroon. Both the countries are treated as Least Developing Countries (LDCs) and in Human Development Index according to Human Development Report of United Nations, they stay at near bottom for instance 146 for Bangladesh and 153 for Cameroon in $2009^{7}$. The indicators pertaining to water holds back their further development in ranking and thus it can be concluded that flawed water management system and policies is the potential responsible reason behind bottom position in human development. On the midst of the Millennium Development Goals, it is not at all desirable to see still many more are crying for a single drop of water. The aspiration of this report has been evolved from this very necessary question of assessing the wrongs in the water policy or concept of IWRM and its' practice within Bangladesh and Cameroon.

\footnotetext{
${ }^{7}$ UNDP, (2009), Human Development Report 2009- Overcoming Barriers: Human Mobility and Development, United Nations Deve- lopment Program.
}

\section{Methodology}

The Methodology report is based on secondary data available in published and unpublished materials e.g. books, journals, magazines, periodical reports, national documents. Rigorous internet searching is one of the major sources of data and information. The consultation with the documents lays the foundation of the report. For situation analysis of the studied countries, non printed internet documents played pioneer role. Literature related to IWRM has been vigorously studied to capture the robust view of $\mathrm{dg}$ the role of IWRM to make the bridge between water management and poverty dimension. Alongside, intergovernmental organizational and development organizational documents, briefing papers, fact sheets provide a peer looking on the situation happening around the world. National documents and policies are the building blocks to depict the country's policies and its state relatedefinin to spirit of IWRM. The report follows the sequential path to reach conclusion as portrayed in Figure 1.

In description of above figure, the goals objective and primary methods of the report have been finalized through consultation between authors. Necessary documents were collected to target the goals and the objectives of the paper. Partially, analyzing policy of third world countries still appears as a cumbersome process because of low level infrastructural development and inadequate information technology systems. Despite such impasses, necessary documents were managed and somewhat translated especially from documents from Cameroon from French into English. This was specific IWRM objectives were then compared against chosen water policy guidelines for the two countries-Cameroon and Bangladesh.

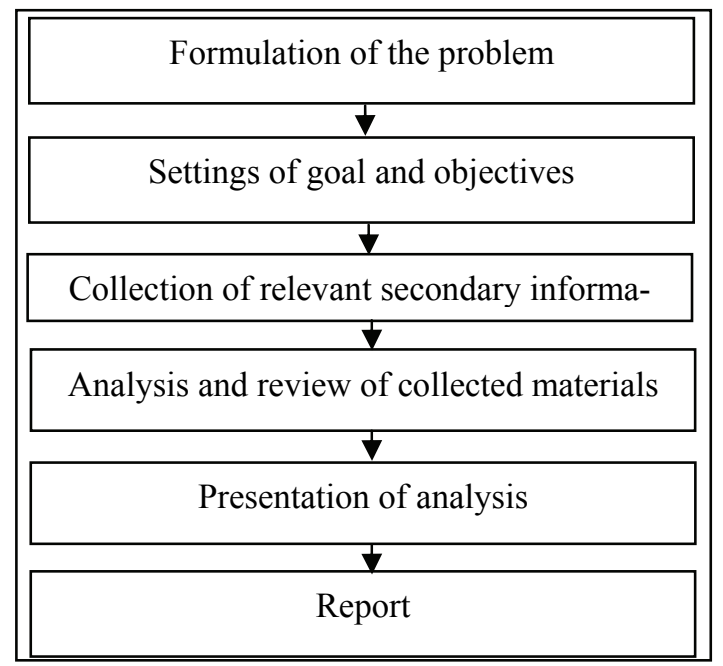

Figure 1. Steps followed to report preparation.

Source: Authors 


\section{Poverty and Water}

\subsection{Cameroon Water Poverty Situation}

Cameroonians in 2001 were living with an annual income below the poverty line of CFAF 232,547 (roughly equivalent to US\$1 per person, per day, or FCFA 19,000 per month), which represents the estimated annual income necessary for an individual in Yaoundé (the capital city) to buy a "minimal basket" of essential food and non-food items, including health, education, and housing expenditures. With the current price hikes in the prices of basic commodities both at the national and international scene, the poverty situation today might even be worst when compared to this 2001 [1].

Water is a basic human need and access to minimum quantities of safe water (20 liters per person per day) should be everyone's right. Lack of access to safe drinking water, sanitation, and irrigation is directly related to poverty and poor health. WHO data shows an average water consumption in 33 countries in Africa stands at 35 litres per person per day a figure seen to be far below minimum average requirement of 50 litres per person per day (WHO, 2008).

Cameroon (West-Central Africa) still live the experiences of the 16th century where safe water for this community has been a farfetched reality; where drinking from the same stream with cattle, pigs, and goats is still very rife and where the ordinary pregnant and farm battered indigenous woman has to trek for kilometres just to fetch water for household use. For the most part, most environs of this community keep on risking their lives to environmental hazards and water borne related epidemics such as diarrhea, cholera and dysentery.

Water resource management in Cameroon is a severe constraint to poverty alleviation and to sustainable development. Significant sections of the population suffer mainly due to poor water management and limited exploitation of existing water sources rather than actual water shortage/scarcity. About $42 \%$ of Cameroonians do not have access to adequate drinking water; this is a striking statistic for a country endowed with abundant freshwater resources. In Cameroon, a cross-section of the population does not enjoy access to water either because the cost to connect the water is too high and/or the cost per meter cube is too high (the cost per meter cube has risen from $339 \mathrm{FCFA} / \mathrm{m}^{3}$ in the 80 's to $470 \mathrm{FCFA} / \mathrm{m}^{3}$ at present-about one US dollar/ $\mathrm{m}^{3}$ ). Given the general financial situation of the people, this amount is too high and this partly explains why water cuts for failure to pay or delays are significantly many.

\subsection{Bangladesh Water Poverty Situation}

With over 1000 people per square kilometers Bangladesh has one of the highest population densities in the world. $50 \%$ of the population is categorized as poor and $20 \%$ as hardcore poor. In absolute numbers, therefore, about 71 million people are under the national poverty line ${ }^{8}$. In spite of this serious challenge, the effort to achieve nearly universal water supply coverage has become an example of global best practice. The water supply coverage reached $97 \%$ in $2005^{9}$ both in urban and rural areas where it was $44 \%$ in $1975^{10}$.

Evidences support that Bangladesh has made commendable progress in supplying safe water to its people. For Bangladesh, the term "water poverty" is thus can be ignored as state is now guaranteeing almost $100 \%$ safe drinking water to its people. Even, nearly same percentage of total population is enjoying safe sanitation system.

This achievement, off-course painted a bright colour on the wall of "water related poverty". No doubt, national policies and all level willingness to meet the target of meeting MDGs played the most significant role. Apart from those policies, nongovernmental organizations contribute a big deal to this achievement and keep the achievement sustained. The projected downside is not much optimistic as growing population, continuous urbanization, irrigation, salanization, climate change and trans-boundary water dispute will likely bring a huge water scarcity and quality related problem in next 25 years if the problems are left unchecked.

Safe drinking water and sanitation is the biggest problem for all developing countries which is being further accelerated due to several physical and social catalysts. Since Bangladesh overwhelmed such a big deal, its water sector problem has taken a paradigm shift from last one decade. The major problem and challenges in water sector that contributes to worsen poverty scenario to other dimension can be categorized as following:

- One of the most critical challenges Bangladesh faces is the management of water resources during their excesses and acute scarcity. It is particularly difficult when only $7 \%$ of the catchments areas of the mighty international rivers, the Ganges, The Brahmaputra and the Meghna are in Bangladesh while $97 \%$ is outside Bangladesh where unfortunately, Bangladesh has no control on upstream diversion and water use ${ }^{11}$.

- There are 57 trans-border rivers including the Ganges, the Brahmaputra and the Meghna out of which 53 come from India, 1 from China and 3 from Myanmar. These rivers carry both huge quantity of floodwaters and sediments. During dry season water is scarce; the rivers

\footnotetext{
${ }_{8}^{8}$ http://siteresources.worldbank.org/INTBANGLADESH/Resources/Ac hievingtheWaterandSanitationMDGsinBangladesh edited.doc on13/05 /2006.

${ }^{9}$ http://hdr.undp.org/en/media/HDR_20072008_EN_Complete.pdf on 13 /05/2009.

${ }^{10} \mathrm{http}: / /$ www.bbs.gov.bd/dataindex/MDGs\%20in\%20Bangladesh.doc.on $13 / 05 / 2009$

${ }^{11} \mathrm{http}: / / w w w . n e w a g e b d . c o m / 2006 / \mathrm{mar} / 04 /$ oped.html on 13/05/2009.
} 
suffer from extreme pollution, not enough water to keep the rivers navigable and not enough water for drinking.

- Low current from upstream rivers causes a huge problem for growing salinization, inadequate supply for irrigation and lowering water tables and lack of stakeholder participation in decision making.

\section{Integrated Water Resources Management (IWRM)}

At its simplest, Integrated Water Resources Management (IWRM) is a logical and appealing concept. Its basis is that the many different uses of water resources are interdependent. Integrated management means that all the different uses of water resources are considered together. Water allocations and management decisions consider the effects of each use on the others. They are able to take account of overall social and economic goals, including the achievement of sustainable development. This also means ensuring coherent policy making related to all sectors. As the basic IWRM concept has been extended to incorporate participatory decision-making. Different user groups (farmers, communities, environmentalists) can influence strategies for water resource development and management.

Management is used in its broadest sense. It emphasizes that it must not only focus on development of water resources but also must consciously manage water development in a way that ensures long term sustainable use for future generations. IWRM considers the viewpoints of human groups, factors of the human environment, and aspects of natural water systems.

Integrated water resources management is therefore a systematic process for the sustainable development, allocation and monitoring of water resource use in the context of social, economic and environmental objectives. It contrasts with the sectoral approach that applies in many countries. When responsibility for drinking water

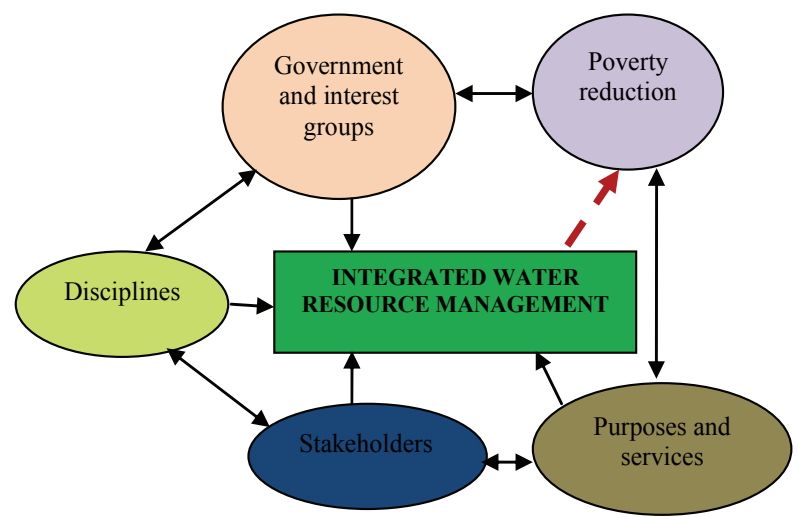

Figure 2. Relationship between IWRM and its components.

Source: Adapted from http://www.waterencyclopedia.com/Hy-La/Integrated-Water-Resources-Management.html. Accessed 13/05/2009. rests with one agency, for irrigation water with another and for the environment with yet another, lack of crosssectoral linkages can lead to uncoordinated water resource development and management, results conflict, waste and unsustainable systems.

According to Global Water Partnership (GWP), IW$\mathrm{RM}$ is based on the equitable and efficient management and sustainable use of water and recognizes that water is an integral part of the ecosystem, a natural resource, and a social and economic good, whose quantity and quality determine the nature of its utilization. The concept of IWRM, thus, introduces a kind of universal definition of IWRM.

Integrated Water Resources Management (IWRM), has been defined as a process which promotes the coordinated development and management of water, land and related resources in order to maximize the resultant economic and social welfare in an equitable manner without compromising the sustainability of vital eco-system ${ }^{12}$.

\subsection{Why IWRM?}

Water is vital for human survival, health and dignity and is a fundamental resource for human development. The world's freshwater resources are under increasing pressure yet many still lack access to adequate water supply for basic needs. Growth in population, increased economic activity and improved standards of living lead to increased competition for, and conflicts over, the limited freshwater resource. Here are a few reasons why many people argue that the world faces an impending water crisis:

- Water resources are increasingly under pressure from population growth, economic activity and intensifying competition for the water among users;

- Water withdrawals have increased more than twice as fast as population growth and currently one third of the world's population live in countries that experience medium to high water stress;

- Pollution is further enhancing water scarcity by reducing water usability downstream;

- Shortcomings in the management of water, a focus on developing new sources rather than managing existing ones better, and top-down sector approaches to water management result in uncoordinated development and management of the resource;

- More and more development means greater impacts on the environment; and

- Current concerns about climate variability and climate change demand improved management of water resources to cope with more intense floods and droughts.

\subsection{Emergence of IWRM as Guiding Principle}

The concept of IWRM has been developed due to illmanagement and non-integrated way of water resource

\footnotetext{
${ }^{12}$ www.unep.org/GC/GCSS-VIII/IWRMFF.OECD.doc on 11/04/2009.
} 
management across the planet. Water is a basic human rights and very much related with the question of bread and butter for the human being from the very first moment when civilization started rolling. Over the time, new categories of water uses have appeared such as industries, irrigation schemes, rapid urbanization and corporate agriculture and etc. Special laws were enacted and special administrations were gradually placed in policy framework for better water management. However, water management was, and in most countries still is, fragmented, without any real taking into account of the global picture. This situation has resulted in many disasters: deprivation of safe drinking water supply, sanitation, intense pollution, overexploitation of aquifers, drying-up of portions of rivers, floods over densely inhabited areas, funds wasted on many inappropriate projects. This state of affairs could not continue indefinitely, and through various means and difficult experiences, a consensus progressively took form: all the users of given water resource should work together in order to try and manage "their" water in the best possible way: IWRM was born ${ }^{13}$.

\subsection{Benefits of IWRM}

\subsubsection{Environmental Benefits}

- Ecosystems can benefit from applying an integrated approach to water management by giving environmental needs a voice in the water allocation debate. At present these needs are often not represented at the negotiating table.

- IWRM can assist the sector by raising awareness among other users of the needs of ecosystems and the benefits these generate for them. Often these are undervalued and not incorporated into planning and decisionmaking.

- The ecosystem approach provides a new framework for IWRM that focuses more attention on a system approach to water management: -protecting upper catchments (e.g. reforestation, good land husbandry and soil erosion control), pollution control (e.g. point source reduction, non-point source incentives, groundwater protection) and environmental flows. It provides an alternative to a sub-sector competition perspective that can join stakeholders in developing a shared view and joint action.

\subsubsection{Agricultural Benefits}

- As the single largest user of water and the major non-point source polluter of surface and groundwater resources, agriculture has a poor image. Taken alongside the low value added in agricultural production, this frequently means that, especially under conditions of water scarcity, water is diverted from agriculture to other water uses. However, indiscriminate reduction in water allocation for agriculture may have far-reaching economic and

\footnotetext{
${ }^{13}$ www.unep.org/GC/GCSS-VIII/IWRMFF.OECD.doc on 06/04/2009.
}

social consequences. With IWRM, planners are encouraged to look beyond the sector economics and take account of the implications of water management decisions on employment, the environment and social equity.

- By bringing all sectors and all stakeholders into the decision-making process, IWRM is able to reflect the combined "value" of water to society as a whole in difficult decisions on water allocations. This may mean that the contribution of food production to health, poverty reduction and gender equity, for example, could override strict economic comparisons of rates of return on each cubic meter of water. Equally, IWRM can bring into the equation the reuse potential of agricultural return flows for other sectors and the scope for agricultural reuse of municipal and industrial wastewaters.

- IWRM calls for integrated planning so that water, land and other resources are utilized in a sustainable manner. For the agricultural sector IWRM seeks to increase water productivity (i.e. more crops per drop) within the constraints imposed by the economic, social and ecological context of a particular region or country.

\subsubsection{Water Supply and Sanitation Benefits}

- Above all, properly applied IWRM would lead to the water security of the world's poor and un-served being assured. The implementation of IWRM based policies should mean increased security of domestic water supplies, as well as reduced costs of treatment as pollution is tackled more effectively.

- Recognizing the rights of people, and particularly women and the poor, to a fair share of water resources for both domestic and household-based productive uses, leads inevitably to the need to ensure proper representation of these groups on the bodies that make water resource allocation decisions.

- The focus on integrated management and efficient use should be a stimulus to the sector to push for recycling, reuse and waste reduction. High pollution charges backed by rigid enforcement have led to impressive improvements in industrial water-use efficiencies in the industrialized countries, with benefits for domestic water supplies and the environment.

- Past sanitation systems often focused on removing the waste problem from the areas of human occupation, thus keeping the human territories clean and healthy, but merely replacing the waste problem, with often detrimental environmental effects elsewhere. Introduction of IWRM will improve the opportunity for introduction of sustainable sanitation solutions that aim to minimize waste-generating inputs, and reduction of waste outputs, and to solve sanitation problems as close as possible to where they occur.

- At a practical local level, improved integration of water resource management could lead to greatly reduced costs of providing domestic water services, if for instance more irrigation schemes were designed with a domestic 
water component explicitly involved from the start.

\subsection{IWRM Principles}

A meeting in Dublin in $1992^{14}$ gave rise to four principles that have been the basis for much of the subsequent water sector reform. These principles form the basis for the in-depth comparative analysis of water related policies in Cameroon and Bangladesh, described in Table 1.

Principle 1: Fresh water is a finite and vulnerable resource, essential to sustain life, development and the environment.

Principle 2: Water development and management should be based on a participatory approach, involving users, planners and policymakers at all levels.

Principle 3: Women play a central part in the provision, management and safeguarding of water.

Principle 4: Water has an economic value in all its competing uses and should be recognised as an economic good as well as a social good.

\section{Translating IWRM from Ideology to Policy - Case of Bangladesh and Cameroon}

The case for IWRM is strong - many would say incontestable. The problem for most countries is the long history of sectoral development. As the Global Water Partnership puts it:

"IWRM is a challenge to conventional practices, attitudes and professional certainties. It confronts entrenched sectoral interests and requires that the water resource is managed holistically for the benefits of all. No one pretends that meeting the IWRM challenge will be easy but it is vital that a start is made now to avert the burgeoning crisis."

IWRM is, above all, a philosophy. As such it offers a guiding conceptual framework with a goal of sustainable management and development of water resources. What it does demand is that people try to change their working practices to look at the bigger picture that surrounds their actions and to realize that these do not occur independently of the actions of others. It also seeks to introduce an element of decentralized democracy into how water is managed, with its emphasis on stakeholder participation and decision making at the lowest appropriate level.

All of this implies change, which brings threats as well as opportunities. There are threats to people's power and position; and threats to their sense of themselves as professionals. IWRM requires that platforms be developed to allow very different stakeholders, often with apparently irreconcilable differences to somehow work together.

Because of the existing institutional and legislative frameworks, implementing IWRM is likely to require reform at all stages in the water planning and manage-

\footnotetext{
${ }^{14}$ The International Conference on Water and Environment, Dublin, Ireland, January 1992.
}

ment cycle. An overall plan is required to envisage how the transformation can be achieved and this is likely to begin with a new water policy to reflect the principles of sustainable management of water resources. To put the policy into practice is likely to require the reform of water law and water institutions. This can be a long process and needs to involve extensive consultations with affected agencies and the public.

Based on the basic principles of the philosophy of IWRM the national water policies of case studied countries have been consulted. This rigorous consultation allows a look into the policy matters how that IWRM has been materialized. This report does not depict any field level practice of those policies but is strictly guided by the policy documents only. Mostly, the table shows synergies and gap among ideological principles, national policies and poverty connection. As the basic premise of this report to make a bridge between philosophy and policy exists compared to poverty situation, the policy related gaps surface in the table. The result of analysis is presented in a matrix form and available in Table 1 below:

\section{Concluding Remarks and Recommendations}

The structured discussion on the basis of the key elements of IWRM reveals that despite of more or less equivalent economic structure of both Bangladesh and Cameroon, both countries do not necessarily have the same policies in water management. A critical look shows that Bangladesh's policies are much more advanced compared to Cameroon. As said earlier, in Water and Sanitation (WATSAN) sector, Bangladesh can be one of the best practice example for the world hence Cameroon WATSAN sector can follow the guiding principles which Bangladesh is following. The implementation system must be different as societal and topographical context is much different.

However, for Bangladesh, due to Arsenic problem ${ }^{15}$ hygienic WATSAN coverage is receding from $97 \%$ to $80 \%{ }^{16}$ [2]. Government should take necessary action not only for meeting arsenic problem but also for projected catastrophe related to water sector.

To manage water resources in a meaningful and effective manner, it seems crucial to incorporate IWRM policies in strata of policy level as cross cutting issue. Development is seen as an integrated and continuous process for sustainability and poverty reduction. IWRM entails the components sustainability which must be incorporated in national development agendas. At the same time, inter-country experience sharing should be encouraged so that good practice can be a universal notion for all. To conclude, the following general recommendations can applied with demystifying properly:

\footnotetext{
${ }^{15} \mathrm{http}: / /$ www.angelfire.com/ak/medinet/file5.html accessed on 13/05 / 2009.

${ }^{16}$ Bangladesh PRSP, 2008.
} 
Table 1. Policy analysis Bangladesh and Cameroon.

\begin{tabular}{|l|}
\hline Components of IWRM \\
\hline Principle 1: Fresh water is a finite and vulnerable \\
resource, essential to sustain life, development and \\
the environment. \\
The freshwater resource is a natural asset that needs \\
to be maintained to ensure that the desired services it \\
provides are sustained. This principle recognises that \\
water is required for many different purposes, func- \\
tions and services; management therefore, has to be \\
holistic (integrated) and involve consideration of the \\
demands placed on the resource and the threats to it. \\
The integrated approach to management of water \\
resources necessitates co-ordination of the range of \\
human activities which create the demands for water, \\
determine land uses and generate waterborne waste \\
products.
\end{tabular}

Principle 2: Water development and managemen should be based on a participatory approach, involving users, planners and policymakers at all levels.

Water is a subject in which everyone is a stakeholder. Real participation only takes place when stakeholders are part of the decision-making process. The type of participation will depend upon the spatial scale relevant to particular water management and investment decisions. A participatory approach is the best means for achieving long-lasting consensus and common agreement. Governments have to help create the opportunity and capacity to participate, particularly among women and other marginalized socia groups. It has to be recognized that simply creating participatory opportunities will do nothing for currently disadvantaged groups unless their capacity to participate is enhanced. Decentralizing decision making to the lowest appropriate level is one strategy for increasing participation.

Principle 3: Women play a central part in the provision, management and safeguarding of water.

IWRM requires gender awareness. In developing the full and effective participation of women at all levels of decision-making, consideration has to be given to the way different societies assign particular social, economic and cultural roles to men and women. There is an important synergy between gender equity and sustainable water management. Involving men and women in influential roles at all levels of water management can speed up the achievement of sustainability; and managing water in an integrated and sustainable way contributes significantly to gender equity by improving the access of women and men to water and water-related services to meet their essential needs.

Principle 4: Water has an economic value in all its competing uses and should be recognised as an economic good as well as a social good.

Within this principle, it is vital to recognize first the basic right of all human beings to have access to clean water and sanitation at an affordable price. Managing water as an economic good is an important way of achieving social objectives such as efficient and equitable use, and of encouraging conservation and protection of water resources. Water has a value as an economic good as well as a social good. Many past failures in water resources management are attributable to the fact that the full value of water has not been recognized.

Cameroon ${ }^{17}[3]$.
According to latest water law of Cameroon
recognize the principal in their article 2,3 and 4.
Those articles recognize that Water is a national
property, thus the state must assure he protection
and management and facilitate access to all. At
the same time article 2 acknowledges the inte-
gration of surface, sub surface, spring and
mineral water sources.
Poverty is another philosophy that is attributed
by water scarcity and deprivation. It is impera-
tive to acknowledge the notion for effective
IWRM for poverty reduction drastically.

IWRM for poverty reduction drastically.

In article 24 traditional authorities are recognized as to competent to regulate litigations related to the use of the water resources on the basis of local custom and habits, without damage of the right of the parts to the litigation to seize the courts of competent jurisdiction of them.

Again article 23 states that parties with a disagreement relating to management of water can regulate it of a common agreement by way of arbitration which implies a kind of notion to manage the water resources with mutual agreement with involved parties.

The direct active participation of all level stakeholders is not however clearly marked which eventually treats end user as just resource user but not as right holders. As long as, user are not recognized as right holders, sustainable water management and poverty eliminating notions will remain as mirage or illusion. Community should have right to put their opinion on policy issues.

As far as water policy of Cameroon concerned no transparent role has been earmarked to woman to leverage the policy.

It is a far dream to ground water policies into practice without active role playing by woman For Cameroon it is an urgent call to incorporate gender friendly policies to move ahead to implement IWRM for poverty reduction.

Article 2 states that water is a national property, thus the state must assure the protection and management and facilitate access to all. Besides, in article 6,16 and 23 contains some indication how water would be treated within the dilemma of public and private goods.

Water is life and it is fundamental rights to human development. At the same time, it is becoming a scare resource all over the world and its magnitude in dry topography like Cameroon is definitely would be hard. From this point of view, government should be strict on its rational use and appropriate pricing for different sectors must be defined.

\section{Bangladesh \\ According to National Water Policy 2001 (Section 2),}

- As water is essential for human survival, socio-economic development of the country and preservation of its natural environment, it is the policy of the Government of Bangladesh that all necessary means and measures will be taken to manage the water resources of the country in a comprehensive, integrated and equitable manner.

- The policies enunciated in the policy are designed to ensure continued progress towards fulfilling the national goals of economic development, poverty alleviation, food security, public health and safety, decent standard of living for the people and protection of the natural environment.

In National Water Policy $2001^{18}$ it is clearly demarcated that (Subsection 4.2)

- The Government recognizes that the process of planning and managing water resources requires a comprehensive and integrated analysis of relevant hydrological, topographical, social, political, economic, environmental and institutional factors across all related water-using sectors.

- According to PRSP 2008 (p-66), the ultimate success and effectiveness of public water resources management projects depends on the people's acceptance and ownership of each project. It is important to delineate the roles and responsibilities of everyone involved in water resources management. The principle that community resources should be managed by the community concerned, along with local government institutions unless a greater national interest prevails, should guide water resource management.

- National Water Policy 2001 recognised that women have a particular stake in water management because they are the principal providers and carriers of water, main caretaker of the family's health, and participants in many stages of pre and post harvest activities (Subsection 4.3a).

- PRSP, 2008 sets five supporting strategies to implement the project fixed in the document. The first supporting strategy is to Ensuring Participation, Social Inclusion and Empowerment of woman in all decision making practice (P-160).

- Changes are required in the system of prices and other economic incentives affecting water demand and supply in Bangladesh. Unless the users pay a price for water, there will be a tendency to misuse and deplete it under scarcity conditions. Desirable practices such as conjunctive use, water-saving agricultural and industrial technologies, water harvesting, water transfers, and water recycling, both within and between sectors, will emerge only when users perceive the scarcity value of water (National water policy 2001, Subsection 4.14).

- The policy related to pricing summarize that, Pricing structure will match the goals and needs of the water provider and the population served. Water rates will be lower for basic consumption, increasing with commercial and industrial use. The rates for surface and groundwater will reflect, to the extent possible, their actual cost of delivery (PRSP, 2008, P-70).

\footnotetext{
${ }^{17}$ All the articles of Cameroon water law have been extracted from LAW N ${ }^{\circ}$ 98-005 of April 14, 1998 on water regime in Cameroon.

${ }^{18}$ www.mowr.gov.bd/Documents/National\%20Water\%20Policy\%20 (English).pdf on 13/05.2009
} 
- Address issues related to the harnessing and development of all forms of surface water and ground water and management of these resources in an efficient and equitable manner.

- Ensure the availability of water to all elements of the society including the poor and the underprivileged, and to take into account the particular needs of women and children.

- Accelerate the development of sustainable public and private water delivery systems with appropriate legal and financial measures and incentives, including delineation of water rights and water pricing.

- Bring institutional changes that will help decentralize the management of water resources and enhance the role of women in water management.

- Develop a legal and regulatory environment that will help the process of decentralization, sound environmental management, and improve the investment climate for the private sector in water development and management.

- Develop a state of knowledge and capability that will enable the country to design future water resources management plans by itself with economic efficiency, gender equity, social justice and environmental awareness.

\section{References}

[1] Republic of Cameroon, Poverty Reduction Strategy Paper (PRSP), 2003-2008, 2003. http://www.imf.org/external/ pubs/ft/scr/2003/cr03249.pdf. Accessed on 26th February 2009.

[2] Poverty Reduction Strategy Paper (PRSP) (2008-2011), Planning Commission Bangladesh National Water Policy, 2008. Ministry of Water Resources, Bangladesh, 2001.

[3] Cameroon Water Law, No 98-005 of April 14, 1998, "On water regime in Cameroon." http://www.gwpcm.org/eng/bibliotheque/File/code\%20cameroun(2).pdf. 